\title{
TENDÊNCIAS CLIMÁTICAS E ANOMALIAS DE PRECIPITAÇÃO EM CARATINGA-MG
}

\author{
Ana Paula Minelli Moreira ${ }^{(a)}$, Ana Luisa Cordeiro Vieira ${ }^{(b)}$, Jaqueline da Consolação Silva ${ }^{(c)}$ \\ (a) Graduanda, Depto. Geografia/Instituto de Geociências, UFMG, anapaulaminelli18@ gmail.com \\ (c) Graduanda, Instituto de Ciências Biológicas, UFMG, ana.cvbio@gmail.com \\ (b) Graduanda, Depto. Geografia/Instituto de Geociências, UFMG, jacquelinecsilva @hotmail.com.br
}

\section{Eixo: Climatologia em Diferentes Níveis Escalares: Mudanças e Variabilidades}

\begin{abstract}
Resumo
$\mathrm{Na}$ análise das médias de temperatura e de pluviosidade referente aos anos de 1961 a 2014, puderam ser identificados eventos climáticos extremos na cidade de Caratinga - MG, Brasil, como o aumento das chuvas em 2013 e a considerável estiagem verificada em 2014. Embora sejam comumente atribuídos a mudanças climáticas causadas pelo homem, tais eventos guardam estreita relação com conjunto de fenômenos climáticos que ocorrem naturalmente na atmosfera, associados à dinâmica das massas de ar.
\end{abstract}

Palavras chave: variabilidade climática, chuvas, massas de ar.

\section{Introdução}

O clima é um agente transformador de ambiente extremamente importante e está em incessante interação com fatores físicos, químicos e biológicos atuantes na crosta e na atmosfera terrestre. O relevo, por exemplo, é moldado, em parte, pela ação intempérica das chuvas e do vento. Em contrapartida, a disposição do relevo molda a direção dos ventos. A vegetação também está em constante interação com o clima. A ocorrência frequente de precipitações nas áreas tropicais, por exemplo, pode propiciar o surgimento de densas florestas, as quais apresentam um elevado índice de evapotranspiração, mantendo o ambiente mais úmido.

Para entender a atmosfera terrestre, é de suma importância compreender a diferença dos termos "mudanças climáticas" e "variabilidade climática" e quebrar concepões pré-estabelecidas. Variabilidade climática é "a maneira pela qual os parâmetros climáticos variam no interior de um determinado período de registro, expressos através de desvio-padrão ou coeficiente de variação" (OMM, 1966), ou seja, são tendências observadas ao longo de anos. O fenômeno El Niño, por exemplo, que é o aquecimento das águas do oceano pacífico, não tem uma periodicidade regular, podendo variar em intervalos de 2 a 14 anos, como ocorreu no ano de 2015, com bastante intensidade, causando fortes chuvas na região sul do Brasil. 
Em contrapartida, mudanças climáticas são alterações do clima, geralmente em grandes escalas espaciais e temporais (séculos e milênios). Um bom exemplo foi a pequena Idade do Gelo, a qual durou cerca de três séculos (1550 a 1850), quando a temperatura do globo declinou significativamente, além de ser um período mais seco. Essas informações puderam ser obtidas através de registros históricos como crônicas e obras de arte.

Desde a formação da atmosfera terrestre, grandes períodos de variabilidade e mudanças climáticas têm ocorrido. O planeta já experimentou desde grandes glaciações até períodos extremamente quentes e áridos. A partir do início do Quaternário, por exemplo, há cerca de 1,5 milões de anos, aproximadamente, uma grande glaciação se sucedeu a cada cem mil anos. A última delas terminou há aproximadamente dez mil anos e atualmente o planeta está passando por uma fase interglacial (SANT'ANNA NETO, 2003).

O clima é extremamente dinâmico, uma vez que tende a apresentar grande variabilidade e mudanças ao longo do tempo geológico. Visto isso, podemos subentender que mudanças climáticas e variabilidade climática são as alterações que o clima apresenta ao longo do tempo buscando adaptar-se. Costumamos ver, principalmente por parte da mídia, esses termos sendo usados para designar as alterações que o homem exerceria no clima do planeta: o chamado aquecimento global, um discurso bastante controverso do ponto de vista científico, defendido por alguns cientistas, mas refutado por outros, como Ricardo Felício, Daniela Onça, Geraldo Luís Lino e Luiz Carlos Molion.

De fato, o ser humano tem sistematicamente causado grandes transformações nos ambientes naturais, especialmente a partir da Revolução Industrial, essas alterações passaram a adquirir proporções cada vez maiores, com a exploração predatória de recursos naturais, erosão do solo, emissão de gases e efluentes tóxicos e geração exorbitante de resíduos.

Entretanto o clima do planeta é extremamente variável, dinâmico e sensível a alterações, mesmo conhecendo alguns dos padrões de comportamento cíclico, não tem sido possível elaborar um modelo de previsão que contemple todas as variáveis intervenientes nos processos climáticos. Isso torna bastante complexa a distinção entre as oscilações climáticas naturais e aquelas decorrentes das atividades humanas (Sant'Anna Neto, 2003). Seria, ainda, descuido afirmar que as temperaturas globais têm aumentado devido à emissão antrópica de dióxido de carbono, se, na realidade, o principal gás de efeito estufa é o vapor d'água, especialmente em termos de quantidade.

A maior dificuldade quando se fala de variabilidade e mudança climática é o não entendimento pleno desses conceitos. É, portanto, imprescindível pensar no objeto de estudo e saber relacioná-lo a estes conceitos, além de levar em consideração os aspectos do clima, como escala espaço-temporal, fatores climáticos e elementos climáticos envolvidos nessa situação. 
Nesse sentido, este artigo tem por objetivo compreender aspectos da variabilidade do clima, através das variações de seus principais elementos (temperatura do ar e totais de chuva) em interação com fatores dinâmicos atmosféricos e da superfície terrestre. Dessa forma, em pesquisas posteriores, poderão ser identificados os impactos sociais e ambientais gerados pelo conjunto eventos associados a esses fatores no município de Caratinga-MG.

A cidade de Caratinga localiza-se a leste do estado de Minas Gerais - Brasil, pertencendo à mesorregião do Vale do Rio Doce. O município, fundado no ano de 1890, é formado atualmente por 11 distritos, com área territorial de $1.250,874 \mathrm{~km}^{2}$, sendo apenas $0,7 \%$ da área pertencente ao perímetro urbano e 99,3\% correspondente à zona rural. A sede do município encontra-se a 578 metros de altitude do nível do mar (Portal do Município de Caratinga - http://www.caratinga.mg.gov.br/).

A cidade é marcada por relevo montanhoso e a vegetação predominante consiste em florestas estacionais semideciduais do domínio Mata Atlântica. Cortada pelo Rio Caratinga, a cidade pertence à Bacia do rio Doce. A urbanização na cidade ocorreu também em direção aos morros, tornando os deslizamentos de terra bastante comuns nos períodos de chuvas. Inundações também são frequentes na estação chuvosa, devido à impermeabilização do solo em determinadas regiões e ocupação irregular da calha fluvial.

O clima de Caratinga é classificado como tropical semi-úmido. O período de insolação anual é de 2.300 horas e a umidade relativa do ar é relativamente elevada, aproximadamente $75 \%$ em média. A temperatura média da cidade é cerca de $20^{\circ} \mathrm{C}$ e a precipitação anual média é de $1.122 \mathrm{~mm}$ (DNMET, 1992).

Caratinga, que está entre as 35 cidades mais populosas do estado, possui 85.239 habitantes, dos quais $82,7 \%$ vivem na área urbana e 17,3\% na zona rural, com densidade demográfica de 67,72 hab/km² (IBGE, 2015). O setor de serviços é, atualmente, o mais relevante na economia de Caratinga, totalizando aproximadamente $73 \%$ do PIB municipal . A indústria e a agricultura são setores menos representativos na economia caratinguense.

\section{Procedimentos Metodológicos}

As séries históricas de dados meteorológicos da cidade de Caratinga foram obtidas através do BDMEP (Banco de Dados Meteorológicos para Ensino e Pesquisa) no site do Instituto Nacional de Meteorologia INMET (www.inmet.gov.br). Foram utilizados dados mensais de precipitação total $(\mathrm{mm})$, temperatura mínima média e temperatura máxima média $\left({ }^{\circ} \mathrm{C}\right)$, relativos ao período entre 01/01/1961 e 31/12/2014. Os anos que tiveram falhas (ausência parcial ou total de dados) foram excluídos desta análise. 
As médias anuais de temperaturas mínimas e máximas e os totais anuais de precipitação foram calculados e utilizados na construção de gráficos no Microsoft Excel, relacionando os anos aos respectivos valores. Foram inseridas linhas de tendência linear para melhor visualização da tendência dos índices de chuva (se estão diminuindo ou aumentando ao longo dos anos) e o índice de correlação $\left(\mathrm{R}^{2}\right)$ em cada gráfico.

Os valores mínimos e máximos absolutos dos dados pesquisados (precipitação total, temperatura mínima média e temperatura máxima média) para cada ano e para todo o período, também foram destacados e organizados em tabelas.

Os valores de anomalias de chuva (\%) foram calculados através da fórmula $(\mathrm{p}-\mathrm{P}) / \mathrm{P} \times 100$, onde: $\mathrm{p}=$ precipitação anual observada $(\mathrm{mm}) ; \mathrm{P}$ = precipitação anual média de todo o período estudado $(\mathrm{mm})$. Os valores de anomalias de temperaturas máximas e de temperaturas mínimas $\left({ }^{\circ} \mathrm{C}\right)$ foram calculados através da expressão $\mathrm{Xi}-\mathrm{X}$, onde: $\mathrm{Xi}=$ temperatura anual; $\mathrm{X}=$ temperatura anual média de todo o período estudado. Foram construídos gráficos relacionando os anos aos respectivos valores de anomalia, para que fosse possível entender melhor os valores que desviam das médias.

A média de precipitação mensal para todo o período em estudo foi calculada e utilizada na construção do gráfico Box Plot de acordo com instruções de Galvani e Luchiari (2012). Os meses que tiveram precipitação entre os $5 \%$ dos menores valores e aqueles entre os $95 \%$ dos maiores valores, foram considerados outliers, ou seja, valores extremos. Para classificação dos meses de cada ano em relação à precipitação, os outliers inferiores foram considerados meses super secos; os valores entre o valor mínimo e o $1^{\circ}$ quartil, meses secos; os valores entre o $1^{\circ}$ e o $3^{\circ}$ quartil, meses normais; os valores entre o $3^{\circ}$ quartil e os valores máximos, meses úmidos; e os outliers superiores, meses super úmidos. A partir desta classificação, foram construídas tabelas e gráficos relacionando o número de meses super secos, secos, normais, úmidos ou super úmidos para cada ano. O Box Plot é de suma importância para melhor observação dos padrões de chuva na área estudada, além de proporcionar boa visualização dos valores extremos.

Foi obtido, através do programa Google Earth, um transecto da cidade de Caratinga, a fim de buscar possíveis relações entre o relevo do local e as características climáticas registradas.

\section{Resultados}

$\mathrm{Na}$ cidade de Caratinga as temperaturas médias estão em torno de $22^{\circ} \mathrm{C}$, com temperatura mínima média de $16,7^{\circ} \mathrm{C}$ e temperatura máxima média de $27,7^{\circ} \mathrm{C}$ (médias calculadas para o período de 1961 a 2014). A 


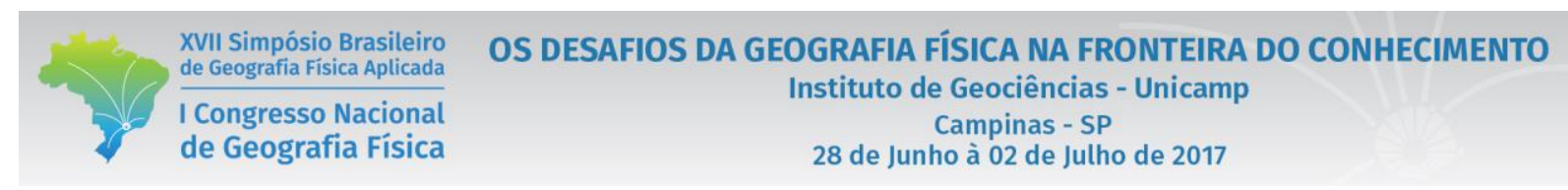

temperatura mínima absoluta para o todo o período foi de $1,3^{\circ} \mathrm{C}$, registrada no dia $16 / 06 / 1975$ e a temperatura máxima absoluta foi de $38,6^{\circ} \mathrm{C}$, registrada no dia $06 / 10 / 2000$.

Até o ano de 1982, as temperaturas máximas e as temperaturas mínimas se mantiveram, na maioria dos anos, abaixo da média. Entre os anos de 1986 a 2005, houve tendência geral de aumento das temperaturas, e a partir de 2005, notou-se que esse contraste diminuiu, uma vez que as temperaturas se mantiveram mais perto da média (figuras 1 e 2). Os gráficos não sugerem nenhuma tendência de aumento de temperaturas com o passar dos anos, visto que o índice de correlação entre as duas variáveis (representado por $\mathrm{R}^{2}$ ) foi baixo tanto para temperaturas mínimas quanto para temperaturas máximas $(0,0177$ e 0,1690 , respectivamente).

A figura 1 e a figura 2 mostram as médias de temperaturas mínimas e máximas, respectivamente, na cidade de Caratinga entre os anos de 1961 a 2014:

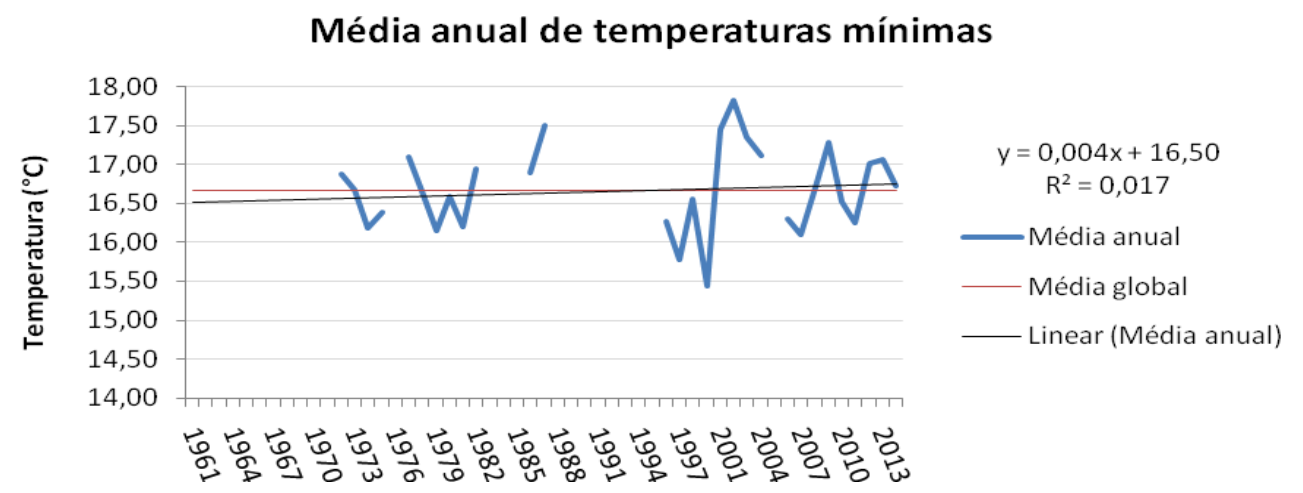

Figura 1- Média anual de temperaturas mínimas em Caratinga nos anos de 1961 a 2014. Elaborado pelas autoras.

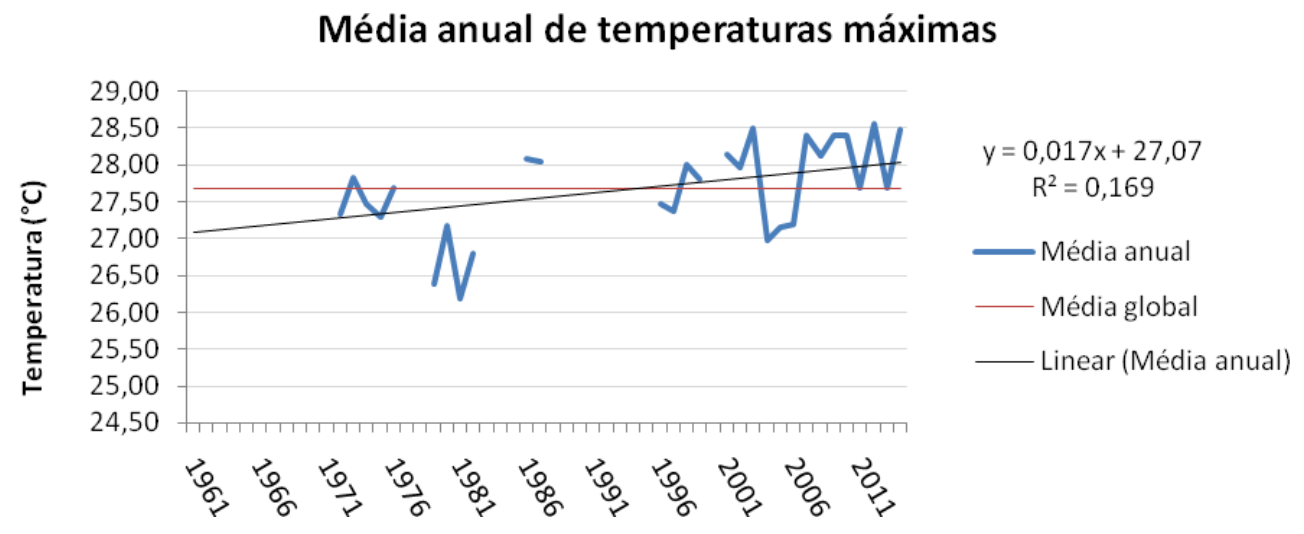

Figura 2- Média anual de temperaturas máximas em Caratinga nos anos de 1961 a 2014. Elaborado pelas autoras. 


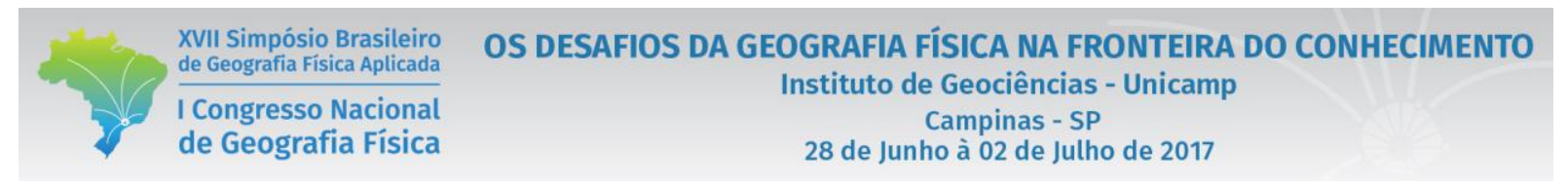

As figuras 3 e 4 mostram a intensidade dos eventos da Oscilação Decadal do Pacífico (ODP) e da El Niño/Oscilação Sul, respectivamente.

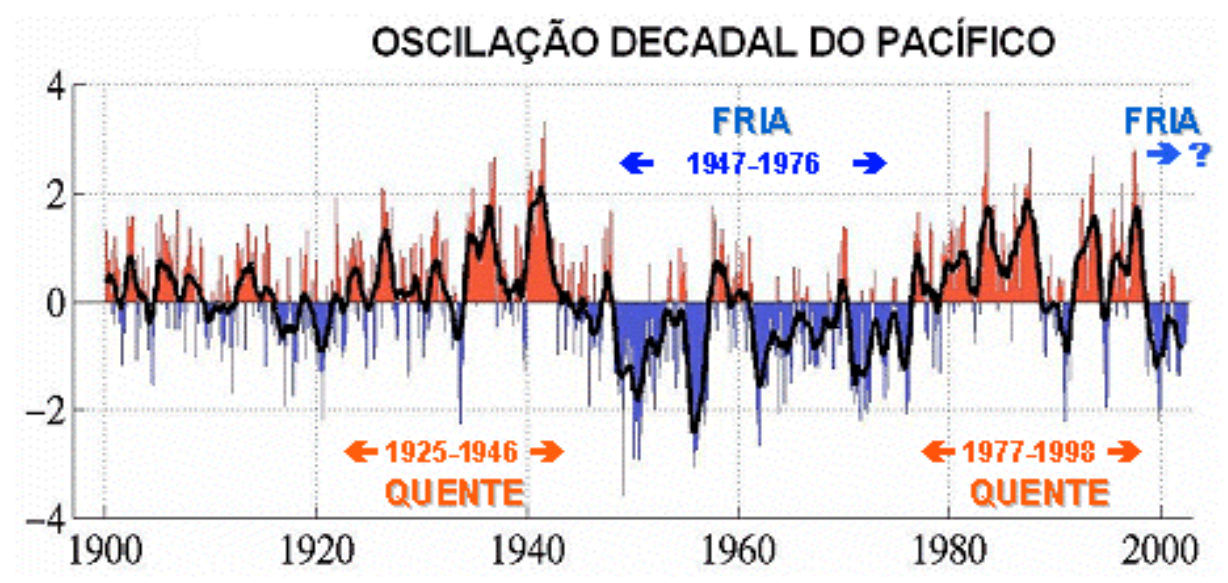

Figura 3- Série temporal da ODP. Fonte: Molion (2005).

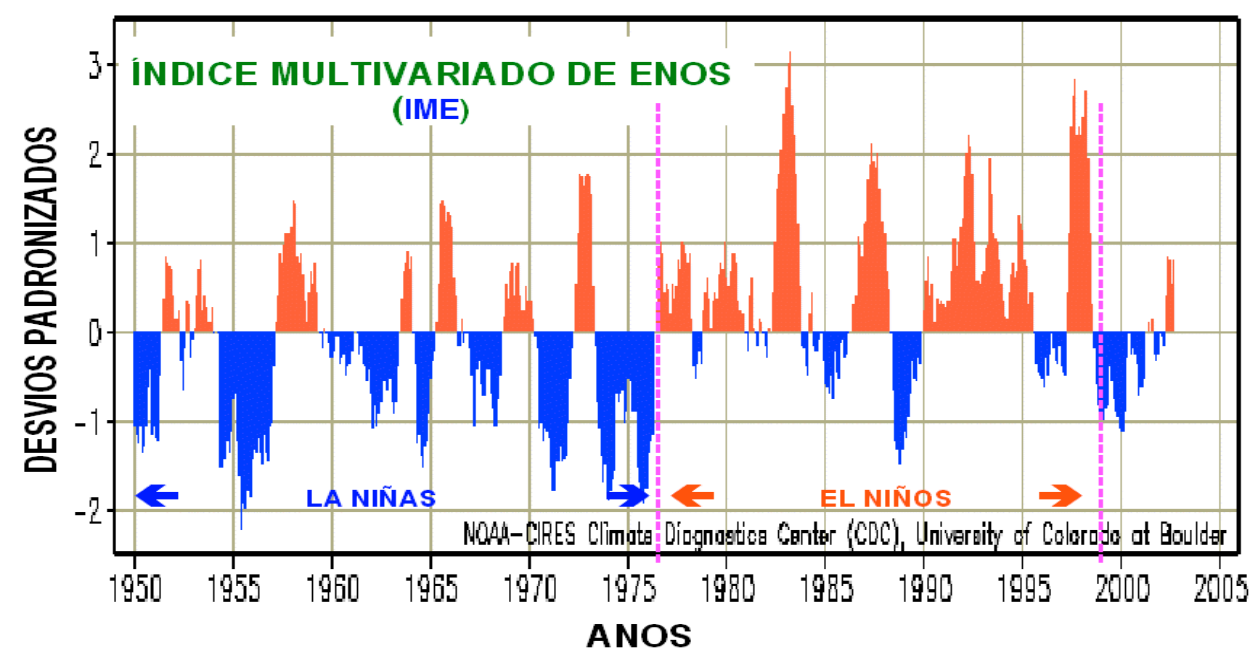

Figura 4- Desvios de temperatura média global causada pelo ENOS. Fonte: Fonte: Molion (2005). Elaborado pelas autoras.

Analisando a série temporal da Oscilação Decadal do Pacífico e do El Niño e La Niña, observa-se que de certa forma, apesar de haver outros elementos e fatores ligados a estas oscilações, esses fenômenos estão relacionados a estas variações de temperatura máxima e mínima e dos totais de chuva na cidade de Caratinga. Por exemplo, no ano de 1975, quando a temperatura do oceano pacífico estava baixa devido à fase fria da ODP e do fenômeno ENOS, percebeu-se que a temperatura mínima e máxima de Caratinga nesse mesmo ano $\left(16,4^{\circ} \mathrm{C}\right.$ e $27,3^{\circ} \mathrm{C}$, respectivamente) esteve abaixo da média $\left(16,7^{\circ} \mathrm{C}\right.$ e $\left.27,7^{\circ} \mathrm{C}\right)$. 
XVII Simpósio Brasileiro de Geografia Fisica Aplicada

I Congresso Nacional de Geografia Física
OS DESAFIOS DA GEOGRAFIA FÍSICA NA FRONTEIRA DO CONHECIMENTO

Instituto de Geociências - Unicamp

Campinas - SP

28 de Junho à 02 de Julho de 2017

A média pluviométrica anual da cidade é de 1122,6 mm, índice relativamente baixo em comparação, por exemplo, com a capital de Minas Gerais, Belo Horizonte (média de chuva $1.460 \mathrm{~mm}$ ), considerando que Caratinga é uma cidade localizada a leste do estado estando, desta forma, mais próxima do Oceano Atlântico do que Belo Horizonte. Essa média pluviométrica inferior ao valor esperado pode ser explicada pelo relevo, uma vez que a cidade está localizada em uma depressão, cercada por serras. Ao transpor a serra, o movimento de compressão do ar na vertente sotavento é acompanhado de elevação da temperatura e distanciamento do ponto de condensação, diminuindo assim a precipitação (efeito orográfico). A cidade de Caratinga se encontra na vertente oeste de uma serra (figura 5).

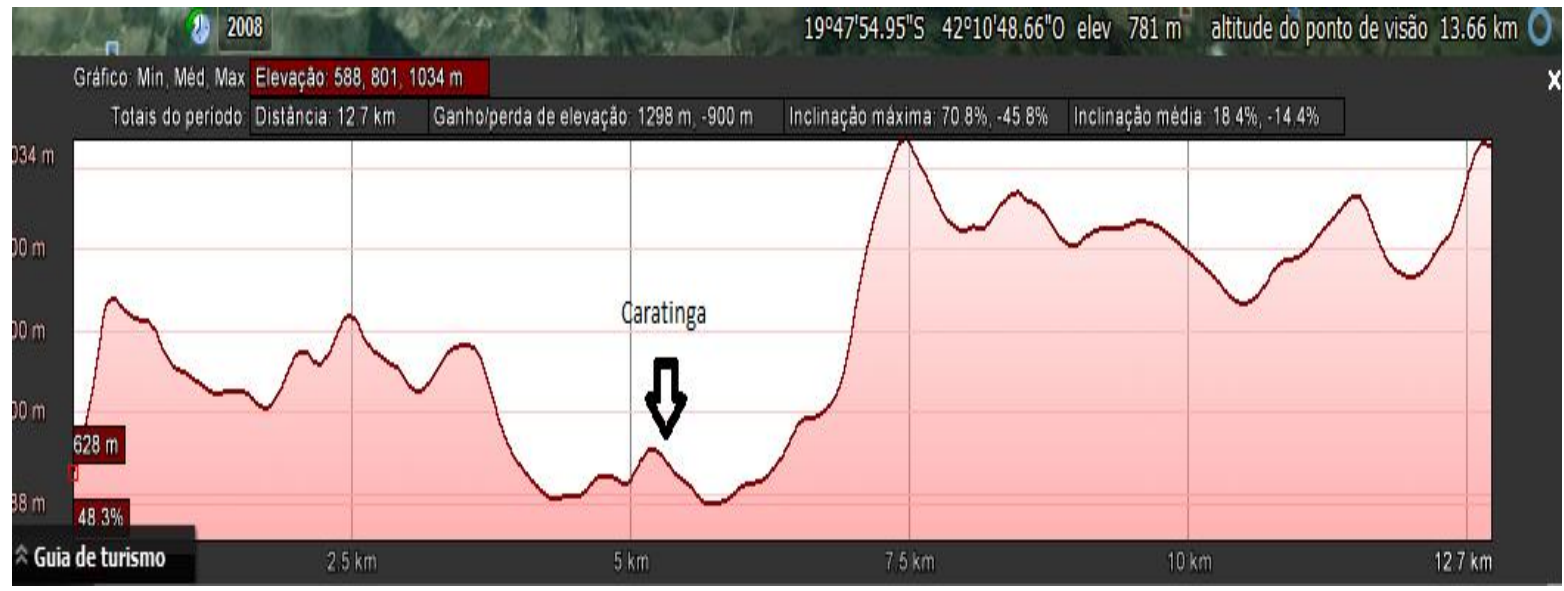

Figura 5- Transecto da cidade de Caratinga. Fonte: Google Earth. Elaborado pelas autoras.

Ainda analisando os índices de chuvas, utilizou-se o gráfico Box Plot, que é usado para explicar a distribuição dos meses super secos, secos, normais, úmidos e super úmidos durante uma série de dados. A figura 6 mostra o gráfico Box Plot para o período entre 1961 e 2014 na cidade de Caratinga. Os valores entre o $1^{\circ}$ quartil e o $3^{\circ}$ quartil correspondem aos meses considerados normais; os valores entre o $3^{\circ}$ quartil e o valor máximo foram considerados úmidos; os meses encontrados entre o $1^{\circ}$ quartil e o valor mínimo são os secos; e os valores representados por pontos foram considerados outliers, fora desses valores. 


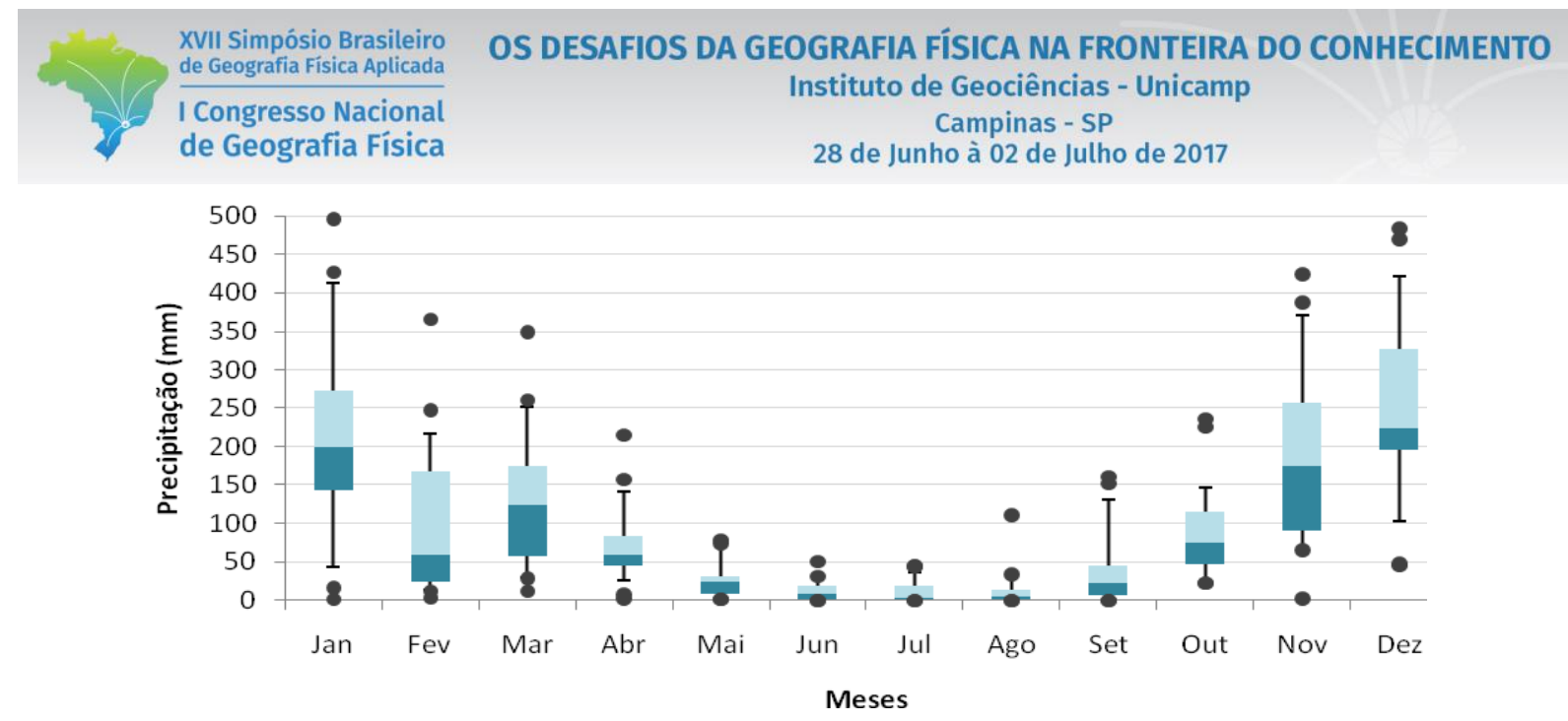

Figura 6- Box Plot pluviométrico de Caratinga. Elaborado pelas autoras.

Analisando toda a série dos acumulados mensais desde 1961 a 2014, pode-se constatar que dos 432 meses avaliados, 16 são considerados super secos (3,7\%), 93 são secos (21,5\%), 215 (49,8\%) são considerados normais, $84(19,4 \%)$ são úmidos e 24 (5,6\%) são classificados como super úmidos. Observou-se também que o mês de fevereiro, considerado úmido, está abaixo desse padrão. Entretanto, os outros meses úmidos (setembro, outubro, novembro, dezembro, janeiro e março) e os meses secos de abril a agosto estão dentro do padrão.

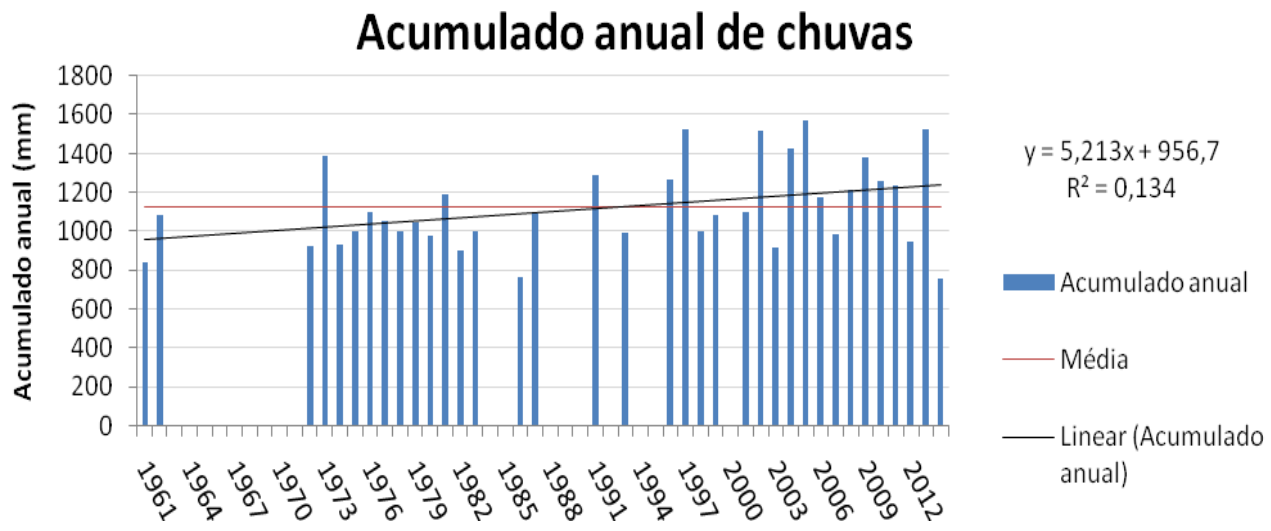

Figura 7- Acumulado anual de chuvas em Caratinga. Elaborado pelas autoras.

Como podemos observar na figura 7, o acumulado anual de 2013 em Caratinga foi de $1.528 \mathrm{~mm}$, valor $36 \%$ acima da média anual de $1.122 \mathrm{~mm}$. Segundo o Instituto Nacional de Meteorologia, esse fato pode ser explicado pela presença da Zona de Convergência do Atlântico Sul (ZCAS) e da Zona de Convergência de umidade (ZCOU) em boa parte do ano na região sudeste, juntamente com a formação de 
frentes frias. A ZCAS é resultado da intensificação do calor e da umidade provenientes do encontro de massas de ar quentes e úmidas vindas da Amazônia e do Atlântico Sul na porção central do Brasil. A ZCOU se assemelha com a ZCAS em vários aspectos, como por exemplo, o fato de serem zonas de convergências que apresentam bastante umidade, porém seu sistema tem duração de apenas três dias. Já as frentes frias, que também atuaram no território brasileiro esse ano, ocorrem quando o ar frio denso empurra o ar quente para cima e para frente, fazendo-o se deslocar da área.

Essas frentes frias tiveram como principal característica o deslocamento rápido e a instabilidade que ocorre quando as diferenças de temperatura e de pressão nas massas de ar são bem acentuadas e causam um grande número de chuvas e trovoadas. Esses dois sistemas (ZCAS e ZCOU), em combinação com as frentes frias atuantes, causam na área onde se deslocam grandes ocorrências de chuvas e nebulosidades, o que explica o fato de em 2013 ter chovido acima da média em várias localidades, incluindo Caratinga, Minas Gerais. Como resultado das chuvas acima da média, a população caratinguense, assim como várias outras em Minas Gerais e no Brasil, sofreu com fortes enchentes, causando mortes, segundo fontes de imprensa.

Em 2014 houve uma anomalia negativa no índice pluviométrico do município, como ocorreu na maior parte da região Sudeste do Brasil, gerando grandes preocupações em relação ao abastecimento de água na região. Foi registrada precipitação anual de apenas $754,3 \mathrm{~mm}$, valor 32,8\% abaixo da média. Durante os meses de janeiro e fevereiro (meses tipicamente chuvosos na região Sudeste), a precipitação total foi equivalente a apenas 26,4\% da média. Dentro da série temporal em análise (1961 a 2014), essa anomalia verificada em 2014 é comparável apenas ao ano de 1986, quando foram registrados $761 \mathrm{~mm}$.

Isso pode ser explicado pelo bloqueio atmosférico que atuou sobre o oceano Atlântico, causado pela intensificação do Sistema de Alta Pressão do Atlântico Sul (ASAS), marcado por uma área estável que oscila entre o Brasil e a África, criando esse intenso bloqueio e impedindo que frentes frias se espalhassem pela América do Sul. A falta de nuvens reduz o albedo que é a capacidade de reflexão de luz solar de volta para o espaço, o que causa aumento da temperatura na superfície. Além disso, houve inibição da frequência de episódios de ZCAS/ZCOU e de sistemas frontais o que, consequentemente, acarretou grande diminuição das chuvas e o aumento da temperatura.

\section{Considerações Finais}

Ao tratar de mudanças e variabilidade climática é necessário a compreensão das escalas espaço-temporais, que são de suma importância para o entendimento da proporção dos mecanismos naturais e ações antrópicas, quando comparadas aos diversos fatores e elementos climáticos que atuam no clima do planeta. Deve-se levar em consideração, ainda, que diversos outros aspectos podem causar variações e 
mudanças no clima terrestre em várias escalas espaciais, como o ciclo das manchas solares, o efeito das

erupções vulcânicas, alterações do campo magnético e da órbita terrestre (Sant'Anna Neto, 2000), além de fenômenos como El Niño, La Niña e a Oscilação Decadal do Pacífico.

\section{Bibliografia}

ACONTECEU. Disponível em:<http://www.plox.com.br/caderno/aconteceu/caratinga-defesa-civil-confirmasegunda-morte-mg-decorrencia-chuva>. Acesso em 6 de dezembro de 2015.

DNMET. Departamento Nacional de Meteorologia. Normais Climatológicas (1961- 1990). Brasília-DF, 1992.

GALVANI, E; LUCHIARI, A. Critérios para a classificação de anos com regime pluviométrico normal, seco e úmido. In. GAlVANI, E; LIMA, N. G. B. (Orgs.) Climatologia aplicada: resgate aos estudos de caso. 1ed. Curitiba: CRV, 2012.

INMET - BDMEP. Dados Históricos. Disponível em: 〈http://www.inmet.gov.br/portal/index.php?r=bdmep/bdmep〉 Acesso em 2 de novembro de 2015.

MARUYAMA, S. Aquecimento global? São Paulo, SP: Oficina de Textos, 2009. 125 p.

MENDONÇA, F.; DANNI-OLIVEIRA, I. M. Climatologia: noções básicas e climas do Brasil. São Paulo: Oficina de Textos, 2007. 206 p.

MOLION, L. C. B. Aquecimento Global. El Niños, Manchas Solares, Vulcões e Oscilação Decadal do Pacífico. Climanálise, ano 3, n.1, 2005.

ORGANIZAÇÃO METEOROLÓGICA MUNDIAL: Climatic Change. Geneva, Switzerland: OMM, 1966. 80p

SANT'ANNA NETO, J. L.; ZAVATINI, J. A. Variabilidade e mudanças climáticas: implicações ambientais e socioeconômicas. Maringá: Eduem, 2000. 259 p.

SANT'ANNA NETO, J. M. Da complexidade física do universo ao cotidiano da sociedade: mudança, variabilidade e ritmo climático. Terra Livre, São Paulo, v.1, n.20, 2003. p.51 - 63.

TORRES, F. T. P.; MACHADO, P. J. O. Introdução à Climatologia - Ubá: Ed. Geographica, 2008. - (Série de Textos Básicos de Geografia), 234 p.

IBGE. Produto interno bruto dos municípios.2012. Disponível em: $<$ http://www.cidades.ibge.gov.br/xtras/temas.php?lang=\&codmun=311340\&idtema=134\&search=minasgerais|caratinga|produto-interno-bruto-dos-municipios-2012>. Acesso: 03/dez. 2015. 